\title{
Cell-wall disruption and characterization of phycocyanin from microalgae: Spirulina platensis using Catalytic ozonation
}

\author{
Rame Rame ${ }^{1, *}$, Nilawati $^{1}$, Silvy Djayanti ${ }^{1}$, Novarina Irnaning Handayani ${ }^{1}$, Agus Purwanto ${ }^{1}$, and Ganang R Dwi \\ Harjanto $^{2}$ \\ ${ }^{1}$ BBTPPI, Jl. Ki Mangunsarkoro No.6, Karangkidul, Semarang Tengah, Kota Semarang, Jawa Tengah, Indonesia 50136 \\ ${ }^{2}$ Neoalgae, Jl. Raya Weru - Tawangsari, Tawang, Weru, Kabupaten Sukoharjo, Jawa Tengah, Indonesia 57562
}

\begin{abstract}
Spirulina is one key material in pharmacy and nutraceutical industries. The cell-wall disruption of Spirulina have been studied for many years, resulting in diverse methodologies with a range of yields and grades of quality. In this paper we report the cell-wall disruption and characterization of phycocyanin from Spirulina platensis using catalytic ozonation. Various parameters of cell-wall disruption such as flow ozone and catalytic time of the reaction were varied to identify the optimum ones. We obtained the phycocyanin with homogeneous size distribution and high ratio could be obtained at flow ozone of 4 LPM, catalytic time of 1 minute and $89.31 \%$ cell-wall disruption yield with $90 \%$ phycocyanin yield. The method reported here is very attractive and potential for production of large scale phycocyanin from microalgae for industrial applications.
\end{abstract}

Keywords: Cell-wall disruption; phycocyanin; spirulina; catalytic ozonation.

\section{Introduction}

Spirulina have a large potential for producing valuable substances for the feed, food, cosmetics and pharmacy industries[1]. Microalgae spirulina are industrially important microorganisms that have been studied largely for bioproducts. Microalgae have been mainly considered for large-scale commercial production, especially for Spirulina. Spirulina is rich in linolenic acid and a good source for polyun- saturated fatty acid (PUFA). Spirulina contains many pigments, including chlorophyll a,xanthophyll, beta-carotene, echinenone, myxoxanthophyll, zeaxanthin, canthaxanthin, diatoxanthin, 3-hydroxyechinenone, beta-cryptoxanthin, oscil-laxanthin, c-phycocyanin, and allophycocyanin. In addition, Spirulina contains about $13.5 \%$ carbohydrates, which is mainly composed of glucose, along with rhamnose, mannose, xylose, galactose, and two unusual sugars, including 2-O-methyl-L-rhamnose and 3-Omethyl-L- rhamnose.

Spirulina also contains over 10-foldmore b-carotene than any other food, including carrots, and more vitamin B12 compared to any fresh plant or animal food source. Compared to green algae, spinach, and liver, this genus represents the richest source of vitamin E, thiamine, cobalamine, biotin, and inositol [2]. Among these compounds, there is C-phycocyanin (C-PC), a photosynthetic pigment found in Spirulina. Phycocyanin is composed of a linear prosthetic groups (bilins) that are linked to specific cysteine residues. Phycocyanin is contain of an apoprotein and a non-protein component (corresponding to the chromo- phore moiety) known as phycocyanobilin (PCB) [3].

Phycocyanin has been widely studied as nutraceutical and health properties that can be used in many industrial applications. In this respect, the use of spirulina and phycocyanin as food supplements for showing antitumor, anti-inflammatory, hepatoprotective, and other health-promoting properties. Other potential industrial applications of spirulina and phycocyanin are used as a natural dye and a good alternative to highly toxic and carcinogenic artificial colorings. Because of its potentially high commercial value, many studies have been directed to improve the efficiency and economics of extraction, isolation and purification processes to produce phycocyanin[2].

Spirulina is known to accumulate high concentrations of phycocianin. The value of 1 kilogram of natural phycocianin has been estimated as high as \$500[4]-[6]. In microalgae-based biorefinement, high-energy and cost-intensive downstream processes such as cell disruption and intracellular products extraction are considered to be major techno-economic bottlenecks.

Recently, the extraction of intracellular phycocyanin from Spirulina, one of most desirable alternative organic nutraceutical, has been a primary focus due to several advantages including high protein productivity, proper nutrition composition for suplement, robustness under outdoor culturing conditions, as well as applications to industrial flue gas utilization and wastewater treatment.

Corresponding author: rameatmopawiro@gmail.com 
On the other hand, tons of Spirulina biomass has been produced annually as a natural source of the high-value strong antioxidant, phycocyanin.

The cell-walls of Spirulina probably represent the biggest barrier to target-phycocianin extraction. Multilayered cell-walls in Spirulina inhibit conventional organic solvents such as hexane's entry to the cell, thereby preventing the proper contact between the organic solvent and intracellular /phycocianin component. Many cell-wall disruption methods have been reported for microalgae in order to maximize the extraction efficiencies of target bioproducts such as phycocianin. However, the selection of appropriate cell disruption and extraction methods is largely dependent on the cell-wall characteristics. The efficiencies of those methods, moreover, are affected significantly by operational conditions such as technology, temperature, pressure, biomass condition and scale.

The development of cell-wall disruption responsible for phycocyanin extraction is an important step in advancing process technologies towards future commercialization of phycocyanin. Many cell-wall disruption methods such as homogenization, ultrasonication, microwave, solvent, acid/base, fenton chemical, hydrolytic enzyme and supercritical $\mathrm{CO}_{2}\left(\mathrm{ScCO}_{2}\right)$ is widely used in studies aimed to develop efficient cell-wall disruption process for phycocyanin extraction [7]-[12]. Although technical scale cell-wall disruption for phycocyanin extraction had been evaluated, a systematic study to examine efficiency parameters important for phycocyanin extraction is still lacking and much needed. This is especially imperative in view of the low yields phycocyanin obtained in a recent study. Catalytic ozonation is a process of AOP (Advanced Oxidation Processes) has been widely utilized in the industry [13]-[17].

We report in this paper our in-depth research on flow ozone preference and catalytic time to improve the efficiency of cell-wall disruption from microalgae spirulina. The information resulted from this research is very attractive and potential for production of large scale phycocyanin from microalgae for industrial applications. This approach is very critical for future development of sustainable cell-wall disruption processes that use lowcost to produce phycocyanin, which is needed to ensure commercial viability of production.

\section{Materials and Method}

Microalgae (Spirulina platensis) biomass contained $15 \%$ moisture content was obtained from CV. Neoalgae (Sukoharjo, Indonesia). The biomass was stored under dry and dark conditions.

The experimental design used a central composite design (four levels) with two variables: flow ozone and time of catalytic. The total run was 16 trials. The flow ozone set at three different levels: 1, 2, 3, 4 LPM and catalytic time of 1,2,3,4 minutes.

In this study catalytic ozonation of $10 \mathrm{~g} /$ hour $\mathrm{kHz}$ ozone and platinum catalyst with a power of $200 \mathrm{~W}$ were used to determine the effect of the frequencies on phycocyanin yield and cell-wall disruption of microalgae
Spirulina platensis. The conventional ozone method was also conducted to compare yield and cell-wall disruption data. We performed digital microscope analysis and spectroscopy analysis using visible spectrofotometer, scanning electron microscope (SEM), transmission electron microscopy (TEM) to obtain data of phycocyanin yield and cell-wall disruption yield of microalgae Spirulina platensis.

\section{Results}

The results of microalgae observation using digital microscope:
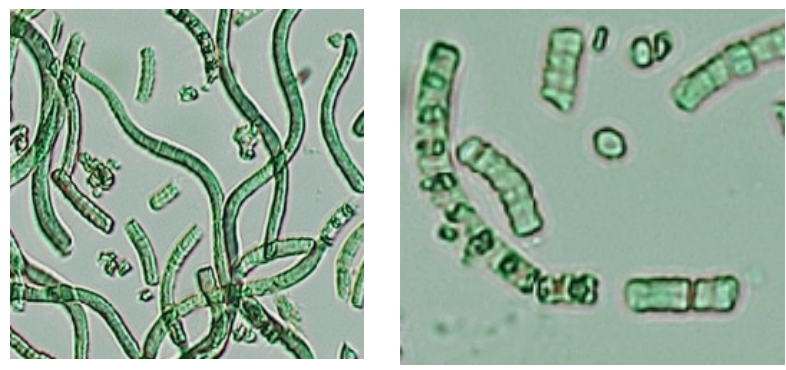

Fig. 1. Digital microscope analysis of Spirulina platensis liquid phase (left) and after catalytic ozonation with Pt catalyst (right).

The results of microalgae testing using scanning electron microscope (SEM):
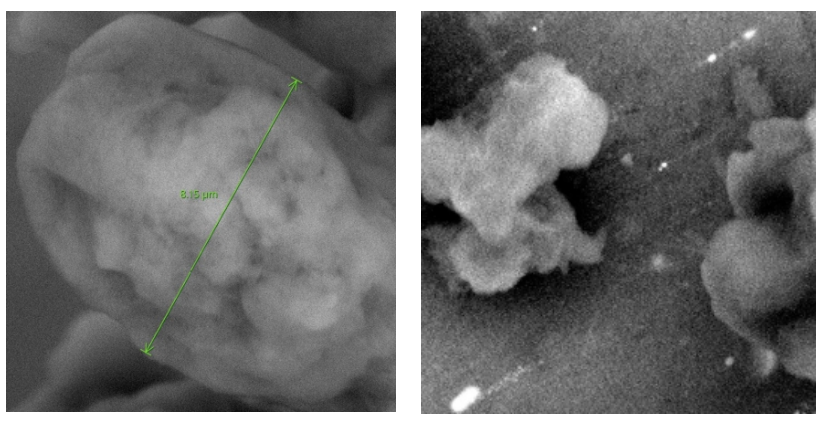

Fig. 2. SEM image of Spirulina platensis cells after augmented aquades (left) and after catalytic ozonation with Pt catalyst (right).

Microalgae test results using Transmission electron microscopy (TEM):
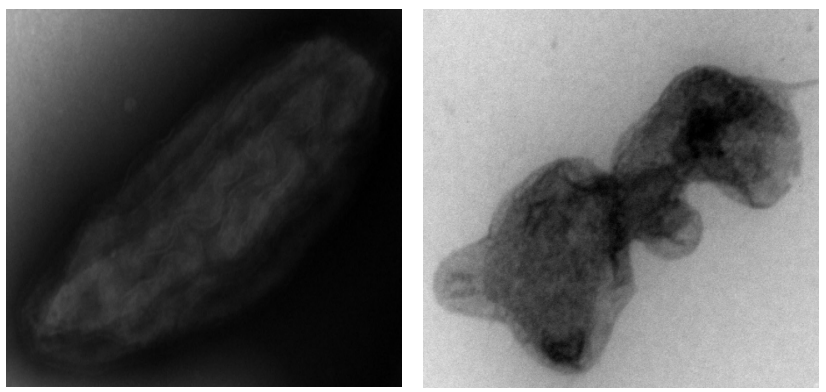
Fig. 3. TEM image of Spirulina platensis cells before treatment (left) and after catalytic ozonization (right).

\section{Discussion}

We observed a significant increase in the phycocyanin yield and cell-wall disruption yield of microalgae Spirulina platensis when using platinum catalyst for catalytic ozonation. This observation contradicted with the results reported previous research [7]-[12]. This difference was likely caused by difference in previous research was many stages, more chemical, and more energy consumed. Previous research used homogenization, ultrasonication, microwave, solvent, acid/base, fenton chemical, hydrolytic enzyme and supercritical $\mathrm{CO}_{2} \quad\left(\mathrm{ScCO}_{2}\right)$. Although no industrial analysis was reported by previous research.

However we worried lots of energy, chemicals, and time wasted during process. Microwave and supercritical $\mathrm{CO}_{2}$ requires very high investment costs, a lot of energy and resource competencies with less satisfactory results [6], [18]-[20]. On the other hand, solvent, acid/base and hydrolytic enzyme requires chemicals with high purity and setting conditions that are quite difficult to achieve [6], [11], [21], [22]. Low cell-wall disruption yield was confirmed using homogenization, ultrasonication, and fenton chemical [6]. Our results was consistent with green industry, where using materials that are environmentally friendly, low energy, and low cost.

The successful isolation of the desired phycocyanin is determined by the disruption of the microalgae cell wall at the catalytic reactor used. Characterization of microalgae cell walls is a very important information of this research. To obtain microalgae cell wall-disruption data, visible spectrofotometer, scanning electron microscopy (SEM), and transmission electron microscopy (TEM) were done. The evaluation of the research was determined based on visible spectrofotometer test results of phycocyanin content on various operating conditions. The result of catalytic ozonation is optimum if the amount of phycocyanin obtained to the raw material and other operational elements is obtained the highest value based on the data analysis from the visible spectrofotometer test results.

Digital microscope observation was performed to find out the breakdown of cell wall as shown in Fig. 1. Spirulina platensis cells before treatment (picture left) appears intact as filamentous nondifferentiated and spiral-shaped. In the sample prepared from Spirulina platensis cells after treatment (picture right), only left part of the cell and the cell wall surrounds the cell unevenly were also observed. Analysis visible spectroscopy was done for calculation of ficocyanin concentration and cell-wall disruption level. The optical properties of fikosianin were measured using a spectrophotometer at $615 \mathrm{~nm}$ and $652 \mathrm{~nm}$ wavelengths, the optical density (OD) values obtained at each wavelength were used to determine the concentration of fikosianin [12].
SEM images of samples microalgae are shown in Fig. 2: from Spirulina platensis cells before treatment (picture left) and prepared from Spirulina platensis cells after treatment (picture right). After treatment with catalytic ozonation, Spirulina formed flakes smaller than $2 \mu \mathrm{m}$ in size. This indicated that there has been activity cell-wall disruption of microalgae Spirulina platensis by catalytic ozonation. In the sample prepared before treatment, the cell is still intact, where the cell shape is still intact, and the cell wall surrounds the cells evenly with size distribution centered around $6 \mu \mathrm{m}$ was observed. The TEM image of the microalgae samples are shown in Fig. 3. In the sample prepared from Spirulina platensis cells before treatment (picture left), the cell is still intact, where the cell shape is still intact, and the cell wall surrounds the cells evenly were observed. In the sample prepared from Spirulina platensis cells after treatment (picture right), only left part of the cell which has changed, where the cell shape is not complete, and the cell wall surrounds the cell unevenly were also observed. This indicated that there has been activity cell-wall disruption of microalgae Spirulina platensis by catalytic ozonation.

Based on the result herein gathered, a protocol was proposed with a one-step cell-wall disruption process in to obtain both a good phycocyanin yield and a high cellwall disruption. This was accomplished by using an aqueous catalytic ozonation with a Pt catalyst, giving phycocyaninin a yield of $90 \%$ and $89.31 \%$ cell-wall disruption yield, thus better the results of previous research. It can be clearly seen that the result value derived from phycocyaninin in the form of crude, so further research is needed for phycocyanin purification.

\section{Summary}

To maximize the phycocyanin benefits that may be obtained from microalgae Spirulina platensis, that essential to seek innovative methods for their cell-wall disruption, and thus preserve the valuable phycocyanin. The current research achieve good phycocyanin yield and cell-wall disruption yield of microalgae Spirulina platensis. The results showed the breakdown of microalgae cell walls can be done through the process of catalytic ozonation. The best catalytic ozonation operating conditions on Spirulina platensis with $\mathrm{Pt}$ catalyst at ozone 4 LPM flow for 1 minute with $89.31 \%$ cell-wall disruption yield and $90 \%$ phycocyanin yield. Electricity consumption for catalytic ozonation operations is relatively lowncompared to other technology so that it can be an alternative in the effort to realize thendevelopment of low carbon communities in the microalgae industry.

\section{Acknowledgements}

This work was supported by the Agency for Research and Industry (BPPI) Grant funded by the Indonesia government Ministry of Industry (2017). 


\section{References}

1. O. Pulz, "Photobioreactors: Production systems for phototrophic microorganisms," Appl. Microbiol. Biotechnol., vol. 57, no. 3, pp. 287-293, (2001).

2. S.-K. Kim, Handbook of Marine Microalgae. Elsevier, (2015).

3. M. G. de Morais, D. da Fontoura Prates, J. B. Moreira, J. H. Duarte, and J. A. V. Costa, "Phycocyanin from Microalgae: Properties, Extraction and Purification, with Some Recent Applications," Ind. Biotechnol., vol. 14, no. 1, pp. 30-37, (2018).

4. J. T. M. Leema, R. Kirubagaran, N. V Vinithkumar, P. S. Dheenan, and S. Karthikayulu, "Bioresource Technology High value pigment production from Arthrospira ( Spirulina ) platensis cultured in seawater," Bioresour. Technol., vol. 101, no. 23, pp. 9221-9227, (2010).

5. E. N. Dewi and L. Purnamayati, "Phycocyanin extraction in Spirulina produced using agricultural waste Phycocyanin extraction in Spirulina produced using agricultural waste," (2017).

6. S. P. Cuellar-bermudez, I. Aguilar-hernandez, D. L. Cardenas-chavez, N. Ornelas-soto, M. A. Romeroogawa, and N. Leon, "Minireview Extraction and purification of high-value metabolites from microalgae: essential lipids, astaxanthin and phycobiliproteins," (2015).

7. C. C. Moraes, J. F. De Medeiros Burkert, and S. J. Kalil, "C-phycocyanin extraction process for largescale use,” J. Food Biochem., vol. 34, no. SUPPL. 1, pp. 133-148, (2010).

8. S. Guan, "Extracting Phycocyanin From Spirulina and Hydrothermal Liquefaction of Its Residues To Produce Bio-Crude Oil,” (2016).

9. H. Horváth, A. W. Kovács, C. Riddick, and M. Présing, "Extraction methods for phycocyanin determination in freshwater filamentous cyanobacteria and their application in a shallow lake Extraction methods for phycocyanin determination in freshwater fi lamentous cyanobacteria and their application in a shallow 1," Eur. J. Phycol., vol. 48, no. 3, pp. 278-286, (2013).

10. N. Abyor, M. Deviana, I. Dianratri, and A. Nugroho, "A Simple Method for Efficient Extraction and Separation of C-phycocyanin from Spirulina platensis," vol. 43, no. March 2005, pp. 15, (2012).
11. J. Yu, "Application of an ultrafine shearing method for the extraction of C-phycocyanin from Spirulina platensis," Molecules, vol. 22, no. 11, p. 22112023 , (2017).

12. Hadiyanto, Suttrisnorhadi, H. Sutanto, and M. Suzery, "Phyocyanin extraction from microalgae Spirulina platensis assisted by ultrasound irradiation: Effect of time and temperature," Songklanakarin J. Sci. Technol., vol. 38, no. 4, pp. 391-398, (2016).

13. Rame, A. Tridecima, H. Pranoto, Moesliem, and Miftahuddin, "FLASH Technology: Full-Scale Hospital Waste Water Treatments Adopted in Aceh," E3S Web Conf., vol. 31, pp. 1-5, (2018).

14. Rame, A. Purwanto, and A. Budiarto, "Treatment of Textile Waste water Based Catalytic Ozonation With Iron (III) Oxide $\left(\mathrm{Fe}_{2} \mathrm{O}_{3}\right)$ and Aluminum Oxide $\left(\mathrm{Al}_{2} \mathrm{O}_{3}\right)$ Catalysts Using Micro Diffuser," Res. J. Ind. Pollut. Prev. Technol., vol. 8, no. 2, pp. 67-75, (2017).

15. C. P. Rivero et al., Current Developments in Biotechnology and Bioengineering. (2017).

16. J. Singh, "Effluent Treatment Plant: Design, Operation And Analysis Of Waste Water," (2012).

17. C. Posten and F. C. Steven, Microalgae Biotechnology, vol. 153. Springer, (2016).

18. R. Vali Aftari, K. Rezaei, A. R. Bandani, and A. Mortazavi, "Antioxidant activity optimisation of Spirulina platensis C-phycocyanin obtained by freeze-thaw, microwave-assisted and ultrasoundassisted extraction methods," Qual. Assur. Saf. Crop. Foods, vol. 9, no. 1, pp. 1-9, (2017).

19. R. Vali Aftari, K. Rezaei, A. Mortazavi, and A. R. Bandani, "The Optimized Concentration and Purity of Spirulina platensisC-Phycocyanin: A Comparative Study on Microwave-Assisted and Ultrasound-Assisted Extraction Methods," J. Food Process. Preserv., vol. 39, no. 6, pp. 3080-3091, (2015).

20. D. Y. Kim et al., "Cell-wall disruption and lipid/astaxanthin extraction from microalgae: Chlorella and Haematococcus," Bioresour. Technol., vol. 199, pp. 300-310, (2016).

21. X. Luo, P. Smith, C. L. Raston, and W. Zhang, "Vortex fluidic device-intensified aqueous two phase extraction of C-phycocyanin from spirulina maxima," ACS Sustain. Chem. Eng., vol. 4, no. 7, pp. 3905-3911, (2016).

22. W. Pan-utai, W. Kahapana, and S. Iamtham, "Extraction of C-phycocyanin from Arthrospira (Spirulina) and its thermal stability with citric acid," J. Appl. Phycol., vol. 30, no. 1, pp. 1-12, (2017). 